\title{
Preliminary report on an ongoing outbreak of hepatitis A in Estonia, 2011
}

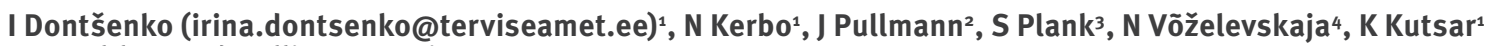

1. Health Board, Tallinn, Estonia

2. Southern Service of the Health Board, Viljandi, Estonia

3. Southern Service of the Health Board, Tartu, Estonia

4. Northern Service of the Health Board, Tallinn, Estonia

Citation style for this article:

Dontšenko I, Kerbo N, Pullmann J, Plank S, Võželevskaja N, Kutsar K. Preliminary report on an ongoing outbreak of hepatitis A in Estonia, 2011. Euro Surveill. Dontšenko l, Kerbo N, Pulr

2011;16(42):pii=19996. Available online: http://www.eurosurveillance.org/ViewArticle.aspx?Articleld=19996

Article published on 20 October 2011

Since the beginning of August 2011, an outbreak of hepatitis $A$ has been detected in Estonia. The majority of laboratory-confirmed cases $(n=66)$ were notified between 4 August and 3 October 2011 and were linked to Viljandi county. The outbreak is still ongoing.

\section{Outbreak description}

Since the beginning of August 2011, an increase in the number of hepatitis A notifications has been observed in Estonia. The majority of cases were notified in Viljandi county or epidemiologically linked to Viljandi county.

In the epidemiological investigation, a case was defined as a person with an acute illness including symptoms clinically compatible with hepatitis $A$, such as fever, fatigue, nausea, vomiting, abdominal pain, dark urine and jaundice, and positive for IgM anti-hepatitis A virus (HAV) identification. In addition, a case was either a resident of Viljandi county, or a resident from another county, who had visited Viljandi city or had had contact with a Viljandi county resident from 4 June 2011 onwards.

Between 4 August and 3 October 2011, 66 confirmed cases of hepatitis A, linked to Viljandi county were notified. This constituted the majority of 71 cases of hepatitis A notified during the same period in Estonia, the highest number of cases $(n=51)$ was notified in September.

The first case notified on 4 August, had onset of symptoms on 24 July and the most recent case, who was notified on 3 October, had symptom onset on 29 September. The majority of cases had onset of symptoms in the period between 18 August and 3 September ( 33 cases) with peaks in week 33 and 35 , suggesting person-to-person transmission. The epidemic curve of the 66 confirmed cases of hepatitis $A$ by date of onset is shown in Figure 1.

\section{FIGURE 1}

Hepatitis A cases by week of symptom onset and county of residence, Estonia, 18 July-9 October $(n=66)$

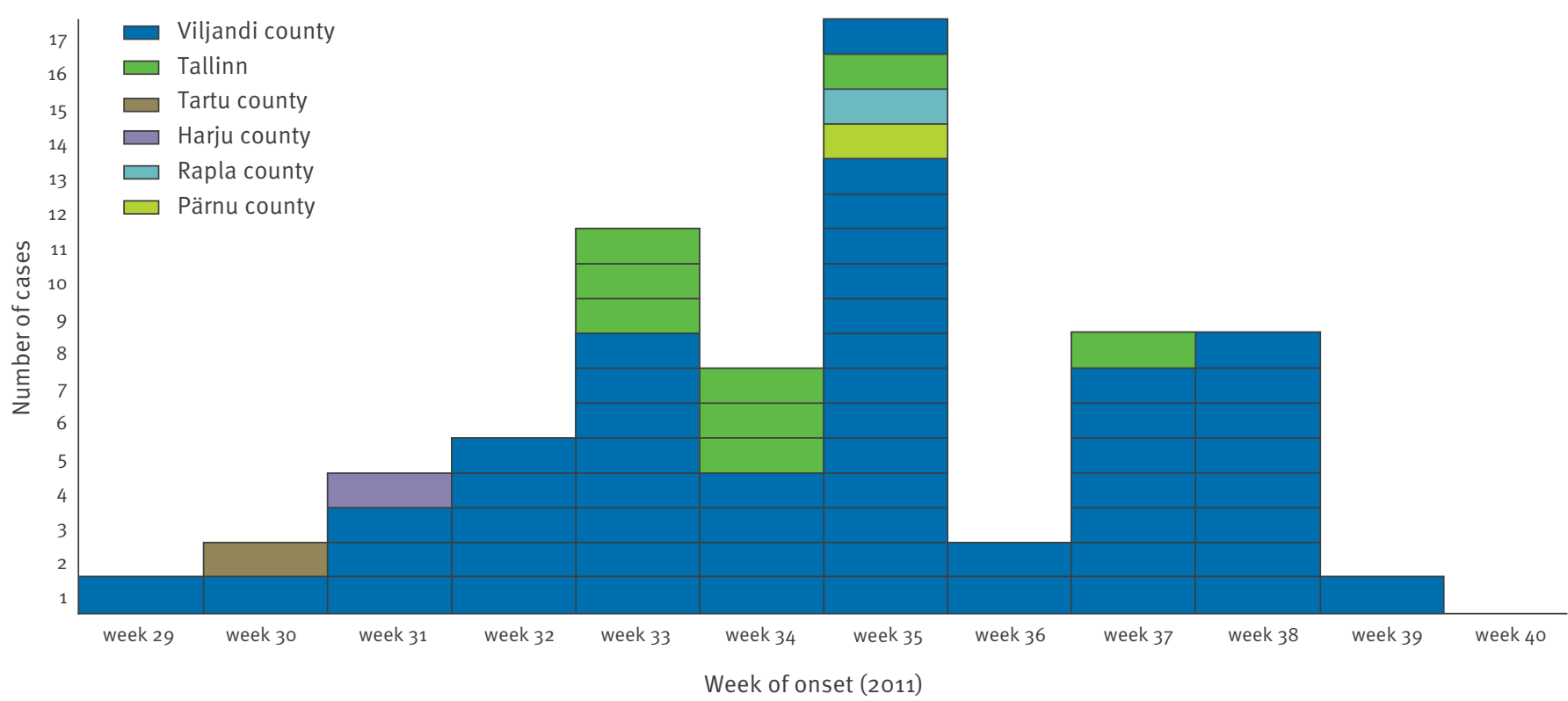


Of a total of 66 cases, 54 were reported from Viljandi county, eight from Tallinn, and one from Tartu, Pärnu, Harju and Rapla counties, respectively. The 12 cases who were not from Viljandi county had either visited Viljandi county or had been in contact with a Viljandi city resident. For Viljandi county, 47 of the cases were Viljandi city residents and seven were part of the rural population.

The age and sex distribution of cases is shown in Figure 2.

The mean age was 33 years (range: $2-78$ years), including 15 cases $(23 \%)$ in children under 14 years of age. Men and women were equally affected.

Due to severe disease and not for isolation purposes, 39 persons were hospitalised with 12 patients in the age group 40-49 years old. Except for one patient, none of the patients had been vaccinated against hepatitis $A$.

Up to 3 October, no acute liver failures or deaths occurred.

\section{Epidemiological situation of hepatitis A in Estonia}

Hepatitis $A$ is a notifiable disease in Estonia. The European Union hepatitis A case definition is used [1]. Laboratory-confirmed cases of hepatitis $A$ are reported by the clinicians to the national surveillance system for communicable diseases NAKIS. Laboratory confirmation of acute HAV infection is performed based on IgM anti-HAV identification. Every confirmed case of hepatitis $A$ is interviewed by the Health Board local service epidemiologist to identify possible common risk factors.

The overall incidence of hepatitis $A$ in Estonia has decreased over the last 13 years from 68.0 per 100,000 population in 1998 to 0.4 per 100,000 in 2010 [2]. The decreasing trend has been attributed to continued

\section{FIGURE 2}

Hepatitis A cases linked to Viljandi county, by age and sex, hepatitis A outbreak, Estonia, 4 August-3 October $2011(n=66)$

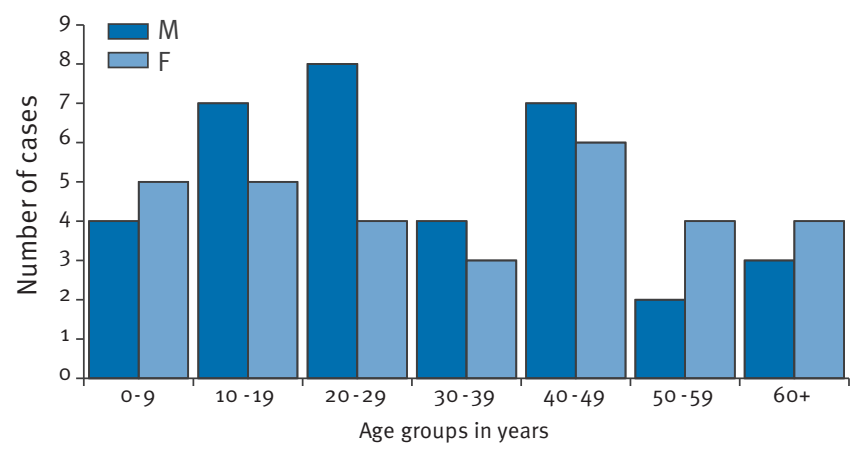

improved sanitary and living conditions, including for example improvement of drinking water quality.

The last outbreak of hepatitis A in Estonia occurred in Lääne-Virumaa county in 1993. It was caused by contaminated water and affected 614 people [3].

During the period from 2006 to 2010, between $60 \%$ and $89 \%$ of hepatitis A cases in Estonia were imported. In 2008, hepatitis A outbreaks were notified in the Czech Republic, Slovakia and Latvia [4-6]. The same year, six cases of hepatitis $A$, notified in Estonia, were related to travel to Latvia, which also resulted in two cases in 2009

Between 1 January and 3 August 2011 only three cases of viral hepatitis A were notified, all travel related. Between 4 August and 3 October 2011, 71 confirmed cases of hepatitis A were reported in Estonia. Of those, three were travel-related with two cases related to travelling to India and one to Belarus.

\section{Measures to contain the outbreak}

The Health Board has prepared HAV prevention guidelines for hospitals, general practitioners, blood centres, food handlers, schools and pre-school establishments. The public is being kept regularly informed about the epidemiological situation via the Health Board website and the media. Increased hand hygiene is recommended for the whole population and for people travelling to affected countries [7].

Post-exposure vaccination of close contacts of confirmed cases within 14 days after the last contact, and traveller's vaccination is recommended [8]. It is of note that vaccination against hepatitis $A$ is not included in the national immunisation schedule and is not free of charge. Vaccination against hepatitis $A$ is only reimbursed by employers, for employees with an occupational risk of infection (for example healthcare workers).

The Health Board has recommended to temporarily stop blood donations from Viljandi county residents during this increase of hepatitis A incidence.

\section{FIGURE 3}

Annual incidence of notifications of hepatitis A per 100,000 population in Estonia, 1998-2010

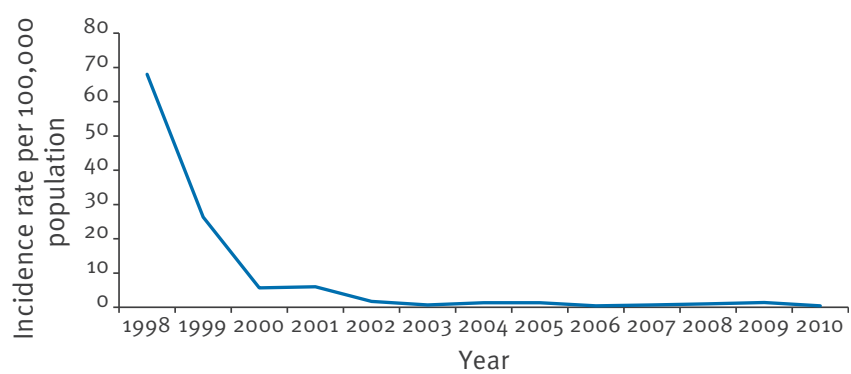


Investigation to find the source of the outbreak

The Health Board has an agreement with the National Institute for Public Health and the Environment of the Netherlands (RIVM) for molecular sequencing. The results of this investigation will provide an opportunity to identify a potential source of infection and to compare the genotypes in this outbreak to those circulating in the previous years in Estonia and to those that are circulating in other countries at the present time.

Suspected modes of transmission in Viljandi are person-to-person transmission and environmental exposure. Drinking water quality and sanitation conditions in Viljandi city met the requirements of national legislative acts. Eighty per cent of citizens are served by a central water supply system based on deep wells and the rest of the citizens are supplied by shallow wells. There was no non-compliance of drinking water quality as well as no accident on the water supply system as well as waste water treatment plant. Therefore contaminated water was excluded as a possible vehicle. Based on veterinarian and epidemiological preliminary investigation results, there is no evidence that contaminated food could be the possible vehicle. The Health Board is planning to conduct a case-control study for cases linked to Viljandi to identify possible common risk factors.

\section{Discussion}

Hepatitis A continues to be one of the most frequently reported vaccine-preventable disease in the world [9]. The virus is present worldwide, and the risk of infection is inversely proportional to levels of sanitation and personal hygiene. With improved sanitation and hygiene, the age of infection shifts to older age groups and consequently the number of persons susceptible to the disease increases over time [10].

The current outbreak of hepatitis A in Estonia, affecting mainly adults over 20 years of age, can be partly explained by the high susceptibility of the population due to a reduced HAV circulation with consecutive lower immunity in the population in the past years that, in the absence of a national vaccination policy, has lead to an accumulation of susceptible individuals [10]. There is a higher risk of more severe disease when hepatitis $A$ is acquired as an adult [9]. This can be relevant for outbreaks in settings where hepatitis A is not endemic. The fact that the biggest age group among hospitalised patients in the current outbreak was between 40 to 49 years old underlines this, however no deaths or acute liver failures were noted so far.

As neither the source of infection nor the mode of transmission have yet been identified, epidemiological investigations by the Health Board are still ongoing in collaboration with hospitals, general practitioners, the Veterinary and Food Board local service, the Ministry of education, the water supply company and the Viljandi county government.
The Health Board has stressed the significance of vaccination against hepatitis $A$ as post-exposure prophylaxis. As HAV vaccination is not included in the national immunisation schedule and many people do not have economical means to cover vaccination expenses, the other main measure taken is to increase awareness of hand hygiene.

\section{References}

1. European Commission. Commission decision of 28 April 2008 amending Decision 2002/253/EC laying down case definitions for reporting communicable diseases to the Community network under Decision No 2119/98/EC of the European Parliament and of the Council. Available from: http:// ec.europa.eu/health/ph_threats/com/docs/1589_2008_en.pdf

2. European Centre for Disease Prevention and Control (ECDC). Annual Epidemiological Report on communicable diseases in Europe 2010. Stockholm: ECDC; 2010. Available from: http://ecdc.europa.eu/en/publications/Publications/1011 SUR_Annual_Epidemiological_Report_on_Communicable_ Diseases_in_Europe.pdf

3. Epidemioloogiline ülevaade, 1993 [Overview of epidemiological situation in Estonia, 1993]. Health Protection Inspectorate. Tallinn, 1994, 140-147. Estonian.

4. Perevoscikovs J, Lucenko I, Magone S, Brila A, Curikova J, Vennema H. Community-wide outbreak of hepatitis A in Latvia in 2008 - an update. Euro Surveill. 2009;14(3):pii=19092. Available from: http://www.eurosurveillance.org/ViewArticle. aspx?Articleld $=19092$

5. Perevoscikovs J, Lucenko I, Magone S, Brila A, Curikova J. Community-wide outbreak of hepatitis A in Latvia, in 2008. Euro Surveill. 2008;13(40):pii=18995. Available from: http:// www.eurosurveillance.org/ViewArticle.aspx?Articleld=18995

6. Cástková J, Beneš C. Increase in hepatitis A cases in the Czech Republic in 2008 - an update. Euro Surveill. 2009;14(3):pii=19091. Available from: http://www. eurosurveillance.org/ViewArticle.aspx?Articleld=19091

7. Health Board, Tallinn, Estonia. Available from: http://www. terviseamet.ee

8. Centers for Disease Control and Prevention (CDC): Manual for the Surveillance of Vaccine-Preventable Diseases (5th Edition, 2011). Atlanta: CDC; 2011. Available from: http://www.cdc.gov/ vaccines/pubs/surv-manual/index.html

9. WHO position paper on hepatitis A vaccines. Can Commun Dis Rep. 2000;26(5):33-8.

10. Payne L, Coulombier D. Hepatitis A in the European Union: responding to challenges related to new epidemiological patterns. Euro Surveill. 2009;14(3):pii=19101. Available from: http://www.eurosurveillance.org/ViewArticle. aspx?Articleld $=19101$ 